\title{
SCIDiC
}

International Journal of Anatomy and Applied Physiology (IJAAP)

ISSN: 2572-7451

\section{Study On Effect Of Exercise On Fasting Blood Glucose Levels}

Research Article

GN Shashi Rekha ${ }^{1 *}$, Asra Anjum² ${ }^{2}$ Supriya Garapati ${ }^{3}$

${ }^{1}$ Associate Professor, Department of Physiology, Mamata Academy of Medical Sciences, Bachupally, Hyderabad, Telangana State, India.

${ }^{2}$ Tutor, Department of Anatomy, Mamata Academy of Medical Sciences, Bachupally, Hyderabad, Telangana State, India.

${ }^{3}$ Professor and HOD, Department of Anatomy, Mamata Academy of Medical Sciences, Bachupally, Hyderabad, Telangana State, India.

\section{Abstract}

Background: Diabetes mellitus (DM) is a group of metabolic diseases characterized by high blood sugar levels over a prolonged period that further produces symptoms like frequent urination, increased thirst and increased hunger. Management of Type 2 Diabetes Mellitus includes Medication or insulin therapy, regular exercise and healthy eating.

Objective: To study the effect of exercise on fasting blood glucose level in non-diabetics at the age of 22-25 years.

Materials and Methods: The study was conducted on 50 medical students. All the volunteers were male students of same age group ranging from 20 to 25 years; they were carefully screened for any significant deviation of health from the normal basal findings. The subjects were made to exercise for 30 minutes and the following observations were recorded.

Results: The mean age of the subject is $22 \pm 2$ years, mean height is $171 \pm 11$, mean weight is $67 \pm 13$ and mean body surface area is $1.8 \pm 0.2$. The mean fasting blood glucose levels before and after exercise is $89 \pm 5$ and $85 \pm 5$ respectively and the $\mathrm{p}$ value is $0.000,1$ which is highly significant.

Conclusion: All forms of exercise produce small benefits in controlling the level of blood glucose. The effects are similar to those of dietary, medication and insulin treatments.

Keywords: Diabetes Mellitus; Insulin Therapy; Exercise; Body Surface Area.

\section{Introduction}

Man is living on the planet earth for over 2,000,000 years. The earlier humans lived a nomadic existence of survival by hunting and gathering food. Their way of life was entirely different from the way people live today in developed countries, and this has profound implications for pattern of disease and associated between living habits and health.

Observation of few remaining nomadic groups in the world indicates that they are relatively free of chronic diseases and are comparatively leaner and have a higher level of physical fitness with higher caloric expenditures per unit of body weight than do modern individuals.

Due to limited active life much progress in the field of exercise and physical condition is taking place. Exercise today has a scientific legitimacy due to research in physical education, exercise physiology and medicine. Muscular exercise is the highest expression of activities of the body and almost all the resources of the body are mobilized in order to bring about the greatest efficiency of Neuromuscular system. With urbanization and fast moving pattern of life, the human being are dependent on vehicular transport and the physical exertion has come to limited level; with the introduction of home appliances, physical exertion of domestic life is also limited. Due to these factors human beings are engaged in fast activities but with limited physical exertion. The main problem of urbanization is a desire or longing for physical exertion. This has led to the concept of centers for tailored or programmed physical activity where subjects are prescribed physical activity based on their age, sex and health status and requirements.

Need for exercise is now a conscious desire of every human being because of increase awareness of hazards of inactive life, like

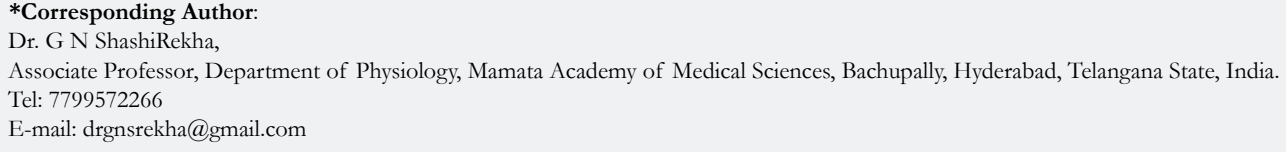

Copyright: GN Shashi Rekha 2020 . This is an open-access article distributed under the terms of the Creative Commons Attribution License, which permits unrestricted use, distribution and reproduction in any medium, provided the original author and source are credited. 
the occurrence of diseases such as Diabetes Mellitus, hypertension, obesity and cardiovascular accidents. These are the chain of diseases with a common base of less active and a more sedentary life which leads to more accumulation and less expenditure of calories. Going by saying " use or loose" either one should use his/her all the body mechanics or loose all and end as a handicap. Mother of diseases, obesity predisposes the individual to increase demands of insulin, which if not available will lead to diabetes mellitus. Diabetes mellitus is a disease which damages all the organs of the body, if not controlled properly and in proper time.

Diabetes is characteristically of two types. Type 1 Diabetes Mellitus, is due to the body's failure to produce sufficient insulin due to an autoimmune condition that causes destruction of the insulin producing beta cells in the pancreas. Type 2 Diabetes Mellitus is characterized by a combination of peripheral insulin resistance and inadequate insulin secretion by pancreatic beta cells. Insulin resistance, which has been attributed to elevated levels of free fatty acids and pro-inflammatory cytokines in plasma, leads to decreased glucose transport into muscle cells, elevated hepatic glucose production, and increased breakdown of fat [1].

Management of Type 2 Diabetes Mellitus includes Medication or insulin therapy, regular exercise and healthy eating. Medications are chosen based on factors such as blood glucose levels and the health problems faced by the patient [2]. Physical activity or structured exercise training used alone or in combination with diet, insulin injections, or oral hypoglycemic drugs are the foundations of therapy for type 2 diabetes [3].

Skeletal muscle is responsible for most of the uptake of glucose after a meal, and transport of glucose into the muscle is considered the limiting step in glucose disposal $[4,5]$. Glucose transport occurs primarily by diffusion utilizing glucose transporter carrier proteins (GLUT). Both exercise and insulin regulate glucose transport mainly by the translocation of the GLUT4 isoform from an intracellular compartment to the plasma membrane and transverse tubules $[6,7]$ GLUT4 levels are considered an important determinant of insulin sensitivity $[4,5]$.

Continuous glucose monitoring (CGM) systems provide continuous, dynamic blood glucose testing, contributing to the discovery of hyperglycemia and hypoglycemia that are not easily detected by traditional monitoring methods [8].

Many people do not exercise despite the proven benefit of endurance exercise. An exercise program requiring less time commitment may appeal to some people. The aim of this paper is to review the impact of high-intensity exercise of short duration on blood glucose levels in diabetic and nondiabetic people.

\section{Materials and Methods}

The study was conducted on 50 medical students. All the volunteers were male students of same age group ranging from 20 to 25 years, they were carefully screened for any significant deviation of health from the normal basal findings. The subjects were made to exercise for 30 minutes and the following observations were recorded.

\section{Collection of Anthropometric data}

Age, Height, weight and Body Surface Area were measured using standard methods.

Measuring the height: The subject was asked to stand on a flat surface and take of his shoes, head bands or anything else from the head that may get in the way of an accurate measurement. The subject was asked to stand against a wall making sure his head, shoulders and buttocks are touching the wall. Line of sight and chin should be parallel to the floor. Using a wall mounted metallic tape measure, the height of the subject is measured.

Measuring the weight: Digital weighing balance was used to measure the weight of the students. Before starting the measurement the scale was adjusted to zero. The students were asked to take off heavy clothings (such as coats, jackets \pm and vests), purses, shoes and heavy accessories such as belts with heavy belt buckles. They should also remove everything from their pockets including money (coins), pens, pencils, wallets, and papers. Each student was asked to step on the scale and stand motionless in the middle of the scale platform with the feet slightly apart and the body weight distributed equally on both feet. Arms should be relaxed and hanging down loosely at the sides of the body. Digital scales are very sensitive to movement and any movement will change the weight measurement, so students must stand very still and the readings were recorded.

Measuring the Body Surface Area: Body Surface Area (BSA) measures the total surface area of the body. The Mosteller formula is most commonly used formula in practice and in clinical trials. The Mosteller formula takes the square root of the height (cm) multiplied by the weight (kg) divided by 3600 .

BSA $(\mathrm{m})^{2}=\sqrt{ }($ Height $(\mathrm{cm})$ X Weight $(\mathrm{kg}) / 3600$

\section{Measuring the Blood Glucose}

Estimation of blood glucose is by King \& ASA Toor Method. Principle: First depolarization is done by using sodium tungstate and enodiols of sugars reduces cupric to cuprous ions, which react with Arsenomolybdic acid and forms molybdenum blue. The blue colored complex formed is measured by colorimeter.

Reagent used: Isotonic reagent, it consists of $\mathrm{Na}_{2} \mathrm{SO}_{4}$ and $\mathrm{CUSO}_{4}$.

1) $\mathrm{Na}_{2} \mathrm{SO}_{4}$ - prevents hemolysis and eliminates non reducing sugars and non carbohydrate reducing acid.

$\mathrm{CUSO}_{4}$ - provides cupric $(\mathrm{CU}++)$ ions

2) Sodium Tungstate - it precipitates the proteins

3) Alkaline Tartrate - Provides alkaline medium and protects cupric ions by complex formation.

4) Arsenomolybdic acid - For color development.

5) Stock - Standard of glucose : It is prepared by adding $100 \mathrm{mg}$ of glucose in $100 \mathrm{ml}$ of Benzoic acid.

6) Working standard of glucose: It is prepared by dissolving $2.5 \mathrm{ml}$ of spot glucose standard in $100 \mathrm{ml}$ of Isotonic reagent.

7) Distilled water:

Procedure:

Depolarization: A solution is made in a test tube by taking $3.8 \mathrm{ml}$ 
of isotonic reagent, $0.1 \mathrm{ml}$ of blood and $0.1 \mathrm{ml}$ of sodium tungstate. Centrifuge the test tube and the superlated layer is protein free filtrate which is kept aside.

Reduction: Take 3 test tubes, label them as test standard and blank. Boil all the test tubes for 10 minutes and cool it for 5 minutes. Adjust the colorimeter to zero by using blank take O.D. value of test and standard at $548 \mathrm{~nm}$ (green filter).

Table showing Reagent Preparation.

\begin{tabular}{|c|c|c|c|}
\hline Reagent & Test & Standard & Blank \\
\hline $\begin{array}{c}\text { Protein free filtrate } \\
(\mathrm{P}++)\end{array}$ & $1 \mathrm{ml}$ & - & - \\
\hline Working standard & - & $1 \mathrm{ml}$ & - \\
\hline Isotonic reagent & - & - & $1 \mathrm{ml}$ \\
\hline Alkaline tartarate & $1 \mathrm{ml}$ & $1 \mathrm{ml}$ & $1 \mathrm{ml}$ \\
\hline
\end{tabular}

Table showing Color development.

\begin{tabular}{|c|c|c|c|}
\hline Reagent & Test & Standard & Blank \\
\hline Arsenomolbdic acid & $1 \mathrm{ml}$ & $1 \mathrm{ml}$ & $1 \mathrm{ml}$ \\
\hline Distilled water & $5 \mathrm{ml}$ & $5 \mathrm{ml}$ & $5 \mathrm{ml}$ \\
\hline
\end{tabular}

\section{Results}

The study was conducted on 50 medical students. All the volunteers were male students of same age group ranging from 20 to 25 years. The mean age and Standard deviation of the students is $22 \pm 2$ years and standard error of mean is 0.3 . The lower limit of the confidence interval (95\%) is 21 years and upper limit is 23 years (Table 1 and Graph 1).

The mean height is $171 \pm 11$ years with standard error of mean
1.7. The lower limit of the confidence interval (95\%) is $167 \mathrm{cms}$ and upper limit is $174 \mathrm{cms}$ (Table 1 and Graph 1).

The mean weight of the students is $67 \pm 13 \mathrm{kgs}$ with standard error of 20. The lower limit of confidence interval (95\%) is $62 \mathrm{kgs}$ and upper limit is $71 \mathrm{kgs}$ (Table 1 and Graph 1).

The mean Body Surface Area (BSA) is $1.80 \pm 0.2 \mathrm{~m}^{2}$ with standard error of mean 0.03 . The lower limit of confidence interval is $1.74 \mathrm{~m}^{2}$ and upper limit is $1.86 \mathrm{~m}^{2}$ (Table 1 and Graph 1).

The mean blood sugar level before and after exercise is $89 \pm 5$ $\mathrm{gm} \%$ and $85 \pm 5 \mathrm{gm} \%$ respectively with standard error of mean 0.8 and 1.0 respectively. The lower limit of confidence interval $(95 \%)$ of blood sugar before and after exercise is $87 \mathrm{gm} \%$ and 84 gm $\%$ respectively. The upper limit of confidence interval $(95 \%)$ of blood sugar before and after exercise is $90 \mathrm{gm} \%$ and $87 \mathrm{gm} \%$ respectively. The $t$ value is 16.13 and $p$ value is $<0.0001$ which is highly significant (Table 2 and Graph 2).

\section{Discussion}

This study was conducted on 50 students of same age group ranging from $20-25$ years, carefully screened for any significant deviation of health from normal basal findings. The subjects were made to exercise for $30 \mathrm{~min}$ and changes in blood sugar levels are observed.

Changes seen in blood glucose level was significantly decrease with mean value of 89 to $85 \mathrm{gm} \%$ with t value of 16.3 and $p$ value $<0.0001$ which is significant.

This fall of blood glucose level is seen in all subjects who were made to exercise hence it can be stated that physical exercise decreases blood glucose level. With the knowledge that during exercise there occurs increase release of catecholamine and ACTH

Table 1. Demographic Data.

\begin{tabular}{|c|c|c|c|c|c|}
\hline \multirow{2}{*}{ Parameters } & \multirow{2}{*}{ Mean } & \multirow{2}{*}{ SD \pm} & \multirow{2}{*}{ SE \pm} & \multicolumn{2}{|c|}{$\begin{array}{c}\text { Confidence } \\
\text { Interval (95\%) }\end{array}$} \\
\cline { 5 - 6 } & & & & LL & UL \\
\hline Age (years) & 22 & 2 & 0.3 & 21 & 23 \\
\hline Height (cms) & 171 & 11 & 1.7 & 167 & 174 \\
\hline Weight (kgs) & 67 & 13 & 20 & 62 & 71 \\
\hline BSA (m $\left.{ }^{2}\right)$ & 1.8 & 0.2 & 0.03 & 1.74 & 1.86 \\
\hline
\end{tabular}

Graph 1. Demographic Date.

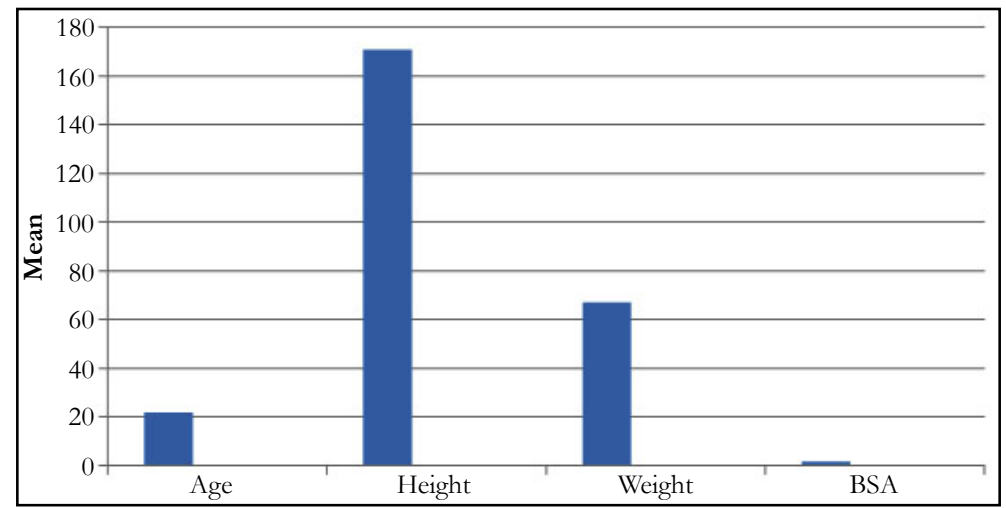


Table 2. Changes seen in blood sugar ( $\mathrm{gm} \%)$ before and after exercise.

\begin{tabular}{|c|c|c|c|c|c|}
\hline \multirow{2}{*}{ Parameters } & \multirow{2}{*}{ Mean } & \multirow{2}{*}{ SD \pm} & \multirow{2}{*}{ SE \pm} & \multicolumn{2}{|c|}{ Confidence Interval (95\%) } \\
\cline { 5 - 7 } & & & & LL & UL \\
\hline Before exercise & 89 & 5 & 0.8 & 87 & 90 \\
\hline After exercise & 85 & 5 & 1 & 84 & 87 \\
\hline
\end{tabular}

$\mathrm{P}$ value $<0.0001$, highly significant

Graph 2. Change in Blood Glucose before and after exercise.

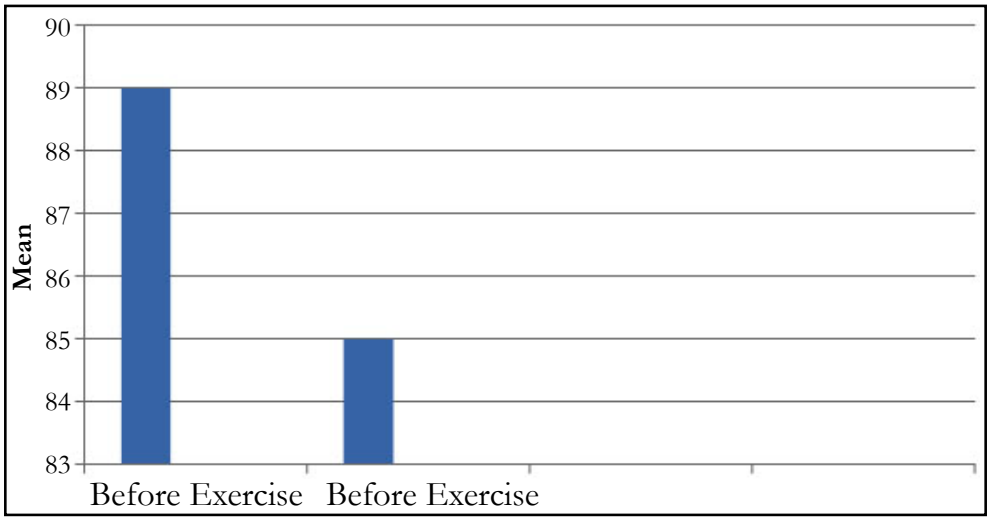

both of which cause glycogenolysis and rise in blood glucose levels. The very fact that instead of rise in blood sugar in exercise there occurs fall in blood sugars, indicate that more and more blood glucose is being utilized by exercising muscle. This supported by study on adreno-receptors present on beta cells of pancreas. These receptors increase insulin secretion.

There is also evidence to show that exercise increases insulin sensitivity of cells, so that blood sugar can more readily be taken within the cells and is utilized. The effect of exercise on blood glucose levels is utilized in prescribing exercise as a part of treatment of diabetes mellitus.

Larsson et al., (1962) noted a lower PWC (physical working capacity) in diabetic adolescent girls compared with normal girls of the same age. They also found a regular decrease in blood sugar of the diabetic girls during work; this effect was especially conspicuous on those girls with a high blood sugar level. After training, PWC increased in most subjects but there was no increase in the insulin requirement in spite of a 50\% increase in caloric consumption [9].

Decreased PWC in diabetic girls was confirmed by Sterky (1963) and in diabetic boys by Larsson et al., (1964) [10, 11]. In the former study, this reduction did not seem to be directly connected with the diabetic state but may have been the result of inadequate training since these diabetic girls were less active than normal girls. Conflicting results on diabetic girls and boys were reported by Elo et al., (1965) who also noted that duration of disease and insulin requirement had a low correlation with PWC [12].

Dangiashwini et al., has compared the fasting blood glucose levels both before and after yoga and aerobics exercise. In both the groups the blood glucose levels decreased and the $\mathrm{p}$ value is 0.0001 which is found to be significant. This author also suggests that both Yoga and aerobic exercise are effective in reducing blood glucose levels in patients with Type 2 Diabetes Mellitus [13].
Management of Type 2 Diabetes Mellitus includes medication or insulin therapy, regular exercise and healthy eating. Medications are chosen based on factors such as blood glucose levels and the health problems faced by the patient. Common medications include Metformin, which improves the sensitivity of the body tissues to insulin and lowers glucose production in the liver. Sulfonylureas are also used and these help the body secrete more insulin. Meglitinides work similar to sulfonylureas except that they are faster acting and do not stay active in the body for long [2].

Yoga, the traditional exercise form, offers a largely unexplored, widely available resource for the management of stress-related ailments. There is evidence that Yoga can benefit patients with Type 2 Diabetes Mellitus. A randomized, controlled trial of Yoga for patients with Type 2 Diabetes Mellitus showed that both Fasting Blood Glucose and Hb1Ac improved significantly along with patients reporting that they felt better, less anxious and more in control of themselves [14].

Type 2 Diabetes Mellitus is characterized by a combination of peripheral insulin resistance and inadequate insulin secretion by pancreatic beta cells. Insulin resistance, which has been attributed to elevated levels of free fatty acids and pro-inflammatory cytokines in plasma, leads to decreased glucose transport into muscle cells, elevated hepatic glucose production, and increased breakdown of fat [1].

These studies suggest that exercise is a useful adjunct to other forms of diabetes management. Unfortunately, most have focused on only one segment of the diabetic population, those taking insulin. This reviewer has found no research on the effects of exercise on the larger number of adult-onset diabetics who are able to control their diabetes by oral hypoglycemic drugs and/ or proper diet. Much more information is needed on the acute and long-term effects of regular exercise and training on the course and severity of the entire spectrum of diabetes mellitus. Again, 
many factors must be controlled before definitive information on exercise can be brought to the attention of the physician and his diabetic patient.

\section{Acknoldegements}

I most humbly acknowledge the students who co-operated me to take the data for the article. I also acknowledge the authors, editors and publishers of all those articles, journals and books from where the literature for this article has been reviewed and discussed.

\section{Conclusion}

Studies on the effect of high-intensity exercise on blood glucose have been few and of short duration, and have involved a small number of patients who were probably not representative of the general diabetic population. With diabetics, it is therefore uncertain if any improvements in blood glucose achieved by a brief intervention would be sustained over a longer period, reduce HbA1c levels, improve health outcomes, and can be replicated in the general dia $\neg$ betic population. Similarly, in the nondiabetic population it is not known whether improvements in insulin sensitiv-ity would be sustained and results in a clinically important endpoint such as diabetes prevention.

\section{References}

[1]. Khardori R. Type 2 Diabetes Mellitus. American Association of Clinical Endocrinologists, American Diabetes Association. The Endocrine Society. 2014; 18(6): 745-749.

[2]. Nathan DM. Initial Management of Glycemia in Type 2 Diabetes Mellitus. NEJM. 2002 Oct; 347(17): 1342-1349.
[3]. Meltzer S, Leiter L, Daneman D, Gerstein HC, Lau D, Ludwig S, et al. Clinical practice guidelines for the management of diabetes in Canada. Can Med Assoc J. 1998; 159 (Suppl. 8):S1- S29.

[4]. Hughes VA, Fiatarone MA, Fielding RA, BB Kahn, CM Ferrara, P Shepherd. Exercise increases muscle GLUT-4 levels and insulin action in subjects with impaired glucose tolerance. Am J Physiol. 1993; 264 (6 Pt 1): E855E862. PMID: 8333511.

[5]. Houmard JA, Egan PC, Neufer PD, JE Friedman, WS Wheeler, RG Israel. Elevated skeletal muscle glucose transporter levels in exercise-trained middleaged men. Am J Physiol. 1991; 261(4 Pt 1): E437-E443. PMID: 1928336.

[6]. Colberg SR, Sigal RJ, Fernhall B, Judith G Regensteiner, Bryan J Blissmer, Richard R, et al. Exercise and type 2 diabetes: the American College of Sports Medicine and the American Diabetes Association: joint position statement executive summary. Diabetes Care. 2010; 33(12): 2692-2696. PMID: 21115771.

[7]. Goodyear LJ, Kahn BB. Exercise, glucose transport, and insulin sensitivity. Annu Rev Med. 1998; 49: 235-261. PMID: 9509261.

[8]. Fonseca VA, Grunberger G, Anhalt H, Timothy S Bailey, Thomas Blevins, Satish K Garg, et al. Continuous glucose monitoring: a consensus conference of the American Association of Clinical Endocrinologists and American College of Endocrinology. Endocrine Practice. 2016; 22(8): 1008-1021. PMID: 27214060.

[9]. Larsson Y, Sterky G, Ekengren K, Moller T. Physical fitness and the influence of training in diabetic adolescent girls. Diabetes. 1962; 11: 109-117. PMID: 14462559

[10]. Sterky G. physical work capacity in diabetic school children. Acta Pediatr. 1963; 52: 1-10. PMID: 13983920.

[11]. Larsson Y, Persson B, Sterky G, Thoren C. Functional adaptation to vigorous training and exercise in diabetic and non-diabetic adolescents. J. Appl Physiol. 1964; 19: 629-635.

[12]. Elo O, Hirvonen B, Peltonen T, Valimaki I. Physical working capacity of normal and diabetic children. Ann Paediatr fenn. 1965; 11: 25-31. PMID: 14292771.

[13]. Ashwini D, Dhwani R, Medha D. A comparative study of the effect of yoga versus aerobic exercise on blood glucose level and quality of life in patients with type 2 diabetes mellitus. Int J Health Sci Res. 2017; 7(1):146-152.

[14]. Viveka P, Ansumali J, Smita Ambekar, Neeta Kumar, Anju Dhawan, Vishnubhatla Sreenivas. Comprehensive yogic program improves quality of life in patients with NIDDM. Indian J Endocrinol Metab. 2012; 16(3): 423 428. PMID: 22629512. 